Keillar for help in taking blood samples. We should also like to thank the Medical Research Council, the Northcott Devon Medical Foundation, and the South Western Regional Hospital Board for financial support.

\section{REFERENCES}

Atherden, L. M. (1958). Biochemical fournal, 69, 75.

Baron, J. H., Nabarro, J. D. N., Slater, J. D. H., and Tuffley, R. (1969). British Medical fournal, 2, 793.

Borst, J. G. G., de Vries, L. A., ten Holt, S. P., and Molhuysen, J. A. (1953). Lancet, 1, 657.

Doll, R., Hill, I. D., and Hutton, C. F. (1965). Gut, 6, 19.
Doll, R., Hill, I. D., Hutton, C. F., and Underwood, D. J. (1962). Lancet, $2,793$.

Elmadjian, F., Hope, J. M., and Pincus, G. (1956). Fournal of Clinical Endocrinology and Metabolism, 16, 338.

Forshaw, J. (1969). British Medical fournal, 2, 674.

Hausmann, W., and Tarnoky, A. L. (1966). British fournal of Pharmacology and Chemotherapy, 26, 412.

Horwich, L., and Galloway, R. (1965). British Medical fournal, 2, 1274.

Khan, M. H., and Sullivan, F. M. (1968). In Symposium on Carbenoxolone Sodium, ed. J. M. Robson and F. M. Sullivan, p. 5. London, Butterworths.

Mattingly, D. (1962). Fournal of Clinical Pathology, 15, 374

Mohamed, S. D., Chapman, R. S., and Crooks, J. (1966). British Medical Fournal, 1, 1581.

Turpie, A. G. G., and Thomson, T. J. (1965). Gut, 6, 591.

\title{
Human Fascioliasis in Shropshire
}

\author{
W. L. G. ASHTON, ${ }^{*}$ B.v.sc., M.R.c.v.s. ; P. L $₫$ BOARDMAN, $\dagger$ M.D., M.R.c.P. ; C. J. D’SA, $\neq$ M.R.c.P. \\ P. H. EVERALL, $\$ F.I.M.L.T. ; A. W. J. HOUGHTON, $\|$ M.R.C.P.
}

Ummary: Five patients with fascioliasis presented with malaise, pruritus, and pain in the right hypochondrium. Eosinophilia, increase in serum gamma globulin, and pyrexia were other features. Four patients treated with oral bithionol recovered completely and it is suggested that this is an effective form of therapy. The double diffusion precipitin test, being speedy and simple, was used as a screening procedure for diagnosis. The source of infection was wild watercress growing in a farm ditch.

\section{Introduction}

The aim of this paper is to describe an outbreak of fascioliasis in humans during which we assessed the response to bithionol (Actamer) and used the double diffusion precipitin reaction as a screening test.

\section{Clinical Description}

\section{The Outbreak}

Case 1.-A housewife aged 22 years was admitted to hospital on 20 December 1968. She complained of attacks of severe pain in the right hypochondrium for three months, loss of appetite, rigors, and weight loss. She had a fever of $39.4^{\circ} \mathrm{C}$. and an enlarged tender liver. Her haemoglobin was $11.6 \mathrm{~g} . /$ $100 \mathrm{ml}$. and the total leucocyte count was 12,000/cu.mm., of which 6,480 were eosinophils. The erythrocyte sedimentation rate was $33 \mathrm{~mm}$. in the first hour (Wintrobe), the serum aspartate transaminase was 28 units, and the serum alkaline phosphatase was $28 \mathrm{King}$-Armstrong units $/ 100 \mathrm{ml}$. The serum albumin was $3.4 \mathrm{~g} . / 100 \mathrm{ml}$. and the globulin $4.5 \mathrm{~g} . / 100$ ml.; paper electrophoresis revealed an increase of alpha-2 globulin and a diffuse increase of gammaglobulin. The Wassermann cardiolipin reaction was positive, but the Treponema pallidum immobilization test and Reiter protein complement fixation test were negative. A needle liver biopsy demonstrated focal granulomata with small areas of necrosis

\footnotetext{
- Veterinary Investigation Centre, Woodthorne, Wolverhampton.

† Consultant Physician, Royal Salop Infirmary, Shrewsbury.

¥ Medical Registrar, Royal Salop Infirmary, Shrewsbury.

Technical Officer, Royal Salop Infirmary, Shrewsbury.

\| Consultant Physician, Royal Salop Infirmary, Shrewsbury.

I Present address: Queen Elizabeth Hospital, Birmingham.
}

heavily infiltrated by eosinophils. Ova of Fasciola hepatica were found in the stools. The fasciola complement fixation test was positive $1 / 80$. The double diffusion precipitin test was also positive. The hydatid complement fixation test and Casoni skin test were negative.

This patient was a member of an isolated farming community. The other members of the community were examined; there was neither clinical nor laboratory evidence of infection in 10 of these. The remaining four are described below.

Cases 2-5 consisted of two men aged 58 and 49 and two females aged 45 and 14 years. All had pain in the right hypochondrium, malaise, and pruritus, and in three the liver was enlarged and tender. Eosinophilia between 2,880-6,000 per cu.mm. was present in all. Ova were found in the stools of one patient. The complement fixation test was positive between $1 / 20$ and $1 / 80$ in three. The double diffusion test was positive in all.

\section{Treatment and follow-up details}

Case 1.-This patient was treated in hospital with emetine hydrochloride $60 \mathrm{mg}$. daily, the 10-day course being interrupted for 48 hours because of atrial ectopic beats. Within a week there was definite symptomatic improvement and ova were no longer found in the stools. After three months she relapsed with abdominal pain for a few days; her erythrocyte sedimentation rate was 40 $\mathrm{mm}$. in the first hour and the eosinophil count was 1,300 per cu.mm. After eight months she was well and had a normal eosinophil count, but precipitin and complement fixation tests were still positive. The Wassermann reaction was negative and the serum alkaline phosphatase normal.

Case 2.-This man was treated with bithionol, $1 \mathrm{~g}$. three times daily orally on alternate days. A few hours after the first dose he had very severe pain in the right hypochondrium and treatment was stopped. Within 10 days of restarting he was symptomfree and ova were not present in his stools. Severe nausea limited the total dosage to $22.5 \mathrm{~g}$., but he recovered completely in six weeks. After eight months he was well, had a normal eosinophil count, but was positive serologically.

Cases 3-5.- Two received $45 \mathrm{~g}$. of bithionol, but the dose for the girl aged 14 was limited to $22 \cdot 5 \mathrm{~g}$. All returned to normal health but experienced nausea and vomiting on the drug. The eosinophil counts returned to normal but the serological reactions remained unchanged after eight months. 


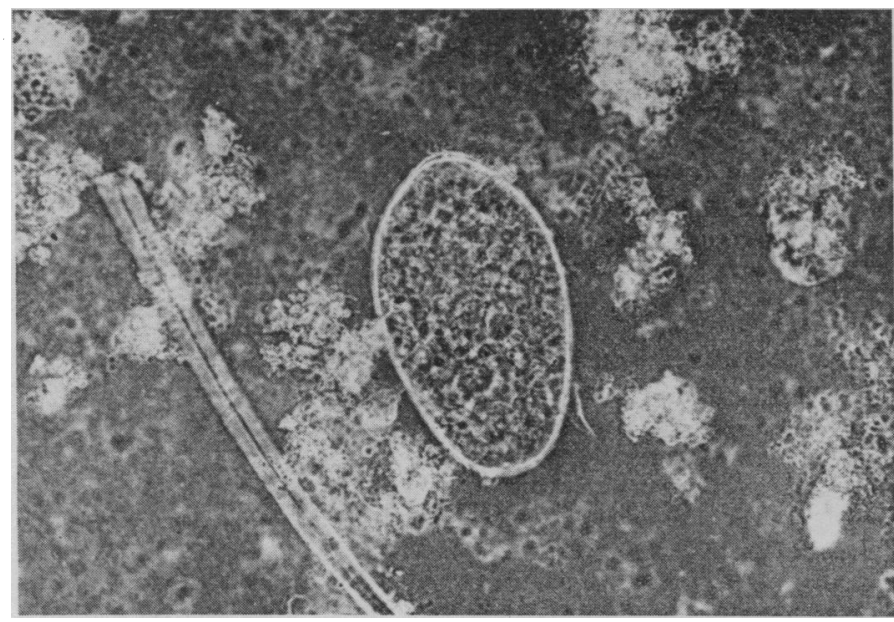

Egg of Fasciola heparica in faeces.

\section{Laboratory diagnosis}

Faeces were examined for ova (see Fig.) after concentration by a modification of the formol-ether centrifugation method (Ridley and Hawgood, 1956). Complement fixation tests were performed by Dr. D. S. Ridley at the Hospital for Tropical Diseases, London. Double diffusion precipitin tests were carried out on the sera of patients and contacts, using as antigen a crude saline extract of adult flukes obtained from the abattoir (Everall, 1970).

\section{Epidemiology}

The liver fluke, $\boldsymbol{F}$. hepatica, is an unsegmented hermaphroditic flatworm of the class Trematoda. It has an indirect life cycle, the adult worm living in the bile ducts of the definitive host, usually a sheep or cow but occasionally man, and the larval form in the intermediate host, which in this country is a small mud-living snail, Limnaea truncatula. From the eggs that are passed out of the faeces of the definitive host ciliated larvae develop under suitable conditions. These are the miracidia, which find and penetrate the body of the host snail. Further metamorphoses take place in the body of the snail, culminating in the production of small tadpole-like creatures, cercariae, which leave the snail and encyst on waterside plants.

If swallowed by the definitive host these encysted stagesmetacercariae or immature flukes-undergo further development until some six weeks later, having crossed the abdominal cavity and burrowed through the liver, they enter the bile ducts, where they grow to maturity. At least six weeks after this the first of the new generation of fluke eggs may appear in the faeces. Since apparently healthy cattle and sheep are often infected with small numbers of liver flukes, and since one fluke can lay 20,000 eggs per day (Taylor, 1964), the incidence of fascioliasis is related to the size of the snail population and, in this, rainfall is the critical factor. In the present outbreak the infected patients lived on two adjacent farms and ate watercress between the months of May and October 1968. The watercress grew wild in two ponds and a ditch on these farms. The ponds were filled with water throughout the year and had clearly defined banks which did not merge into marshy areas and did not constitute typical $L$. truncatula habitats. A thorough search around both ponds failed to reveal any snails. The ditch ran alongside the road to the farms and received tributaries from the adjacent fields. Watercress grew conveniently in the ditch by the gate of one farmhouse. A search here in January 1969 revealed numerous live snails identifed as $L$. truncatula. Dissection showed that 20 of the 50 snails collected were infected with rediae and cercariae of $\boldsymbol{F}$. hepatica.

Foot-and-moath disease had been confirmed on both farms in November 1967. Restocking began in June 1968, when 45 cattle were brought on to the two farms from an area where fascioliasis is endemic. Under favourable conditions eggs can reach the infective metacercariae stage in 11 weeks (Ollerenshaw, 1969). Thus, assuming that the parasite was introduced by the purchased cattle, the human infections could not have occurred before the middle of August. After diagnosis of the human outbreak fascioliasis was confirmed in the cattle on the two farms.

\section{Discussion}

All patients had eosinophilia, pain in the right hypochondrium, malaise, and pruritus. Weight loss, pyrexia, tender hepatomegaly, and a diffuse increase of serum gammaglobulin were noted in four. The person with minimal symptoms (Case 5) was treated, in spite of the possibility of spontaneous cure (Taylor, 1961), because of the risk of late bile duct obstruction.

Emetine hydrochloride and chloroquine are the two main therapeutic agents. In this series Case 1 responded to emetine, but its disadvantages are cardiac toxicity and the need for parenteral administration. Facey and Marsden (1960) reported dramatic improvement on chloroauine sulphate, but ova continued to be found in the stools, and a high incidence of side-effects was recorded.

Bithionol is used to treat the lung fluke, Paragonimus, sideeffects being transient diarrhoea, abdominal pain, nausea, anorexia, and urticaria (Kang, Loh, Ham, and Chyu, 1963). It is effective against induced fascioliasis in rats (Dawes, 1966). Swiezawska, Kaliszewicz, and Grott (1967) have reported success in a case of human fascioliasis. The four outpatients in this series treated with bithionol recovered completely, their cosinophilia resolved, and ova were not derected in the faeces, but complement fixation and precipitin reactions remained positive. Side-effects were nausea, vomiting, diarrhoea, abdominal pain, and pruritus. In one patient the dose had to be limited to $22.5 \mathrm{~g}$., but the response was still satisfactory, suggesting that the effective dose may be lower than that emploved. The intense pain that developed in Case 2 a few hours after the initial dose suggested the possibility of a Herxheimer type of reaction.

A minimum of three months elapses between the time of ingestion of metacercariae bv the human host and the appearance of eggs in the faeces. In many human infections the larval flukes do not develop to marurity; thus Coudert (1960) recorded that in $30 \%$ of over 100 cases eggs were never found in the faeces or bile. Serological tests are therefore of importance in the diagnosis of this disease. The one most commonly used in this country is the complement fixation test. This requires specialized knowledge for antigen preparation and performance if it is to maintain specificity and sensitivity. Double diffusion analvsis offers great advantages of speed and simplicity and in addition allows direct comparison between different serum samoles. Positive reactions may occur in patients infected with other helminths (Capron, Biguet, Tran Van Ky, and Rose, 1964). However, the production of more than one precipitin line in this test and the reaction of identity support the diagnosis, and in this country at least it appears to be of value as a screening test.

During 1969 there were at least three other outbreaks of liver fluke disease in man in the United Kingdom, a feature common to all being a history of eating wild watercress (Tee, 1969). In general, cultivated watercress is safe (Public Health Laboratory Service, 1966; Lancet, 1969). After wet summers, however, when an increase in the incidence of fascioliasis can be predicted, the danger of earing wild watercress or watercress of unknown origin should be publicized.

We wish to thank Dr. D. S. Ridley for his help and to acknowledge the assistance of all sections of the department of pathology at the Royal Salop Infirmary. 


\section{Rmprarances}

Capron, A., Biguet, J., Tran Van Ky, P., and Rose, E. (1964). Presse
Médicale, 72, 3103. Coudert, J. (1960). Pathologie et Biologie, 8, 145.

Dawes, B. (1966). Nature, 209, 424.

Bverall, P. H. (1970). Fournal of Clinical Pathology. In press.

Facey, R. V., and Marsden, P. D. (1960). British Medical Yournal, 2, 619.

Keng, S. Y., Loh, I. K., Ham, E. K., and Chyu, I. (1963). Youmal of the Korean Medical Association, 6, No. 8, p. 59.

Lancet (1969), 1, 658.
Ollerenshaw, C. B. (1969). Personal communication.

Public Health Leborntory Service. (1966). Monthly Bulletin of the Miristry of Health and the Public Laboratory Service, 25, 146.

Ridley, D. S., and Hawgood, B. C. (1956). Yournal of Clinical Pathology, 9,

Swiezawrika, E., Kaliszewicz, S., and Grott, J. W. (1967). Wiadomości Parasytologicene, 13, 707.

Taylor, A. W. (1961). Lancet, 2, 1334.

Taylor, B. L. (1964). Fascioliasis and the Liver Fluke. Rome, F.A.O.

Tee, G. (1969). Lancet, 1, 778.

\section{$\varnothing_{\text {Fascioliasis-A Large Outbreak }}$}

E. W. HARDMAN;* M.B., CH.B. ; R. L. H. JONES, * M.B., B.CH. ; A. H. DAVIES, ${ }^{*}$ M.B., D.OBST.R.C.o.G.

British Medical fournal, 1970, 3, 502-505

\begin{abstract}
Cummary: Forty-four cases of liver fluke infestation (fascioliasis hepatica) were diagnosed near Chepstow, Monmouthshire, in 1968. Intramuscular emetine hydrochloride and oral chloroquine given to the adults and children, respectively; were well tolerated. Assessment by repeated stool examination, complement fixation and liver function tests, and full blood counts indicated that treatment had been effective in most cases. It is recommended that both the growth and the sale of watercress should be strictly controlled.
\end{abstract}

\section{Introduction}

The outbreak reported here is by far the largest to have occurred in Britain. Facey and Marsden (1960) described six cases in Hampshire in 1959. Apart from this outbreak, human generalized fascioliasis has been described only in isolated cases in the United Kingdom. Two cases have been reported in Kent (Taylor, 1961) and one in a farm worker from Scotland (Jones and Smith, 1963). The disease is much more common abroad, a well-documented outbreak of 53 cases having occurred in France (Pautrizel et al., 1964), as well as 12 cases in Algeria (Coumbaris, 1966). One interesting case was that of an 8-year-old boy who was treated with intravenous emetine with apparently good results (Quaiser, 1956).

Adult flukes may be found in widespread sites-for example, subcutaneous tissue, brain, and bladder-and several cases of ectopic fascioliasis have been described (Bürgi, 1936; Catchpole and Snow, 1952); one of the cases in this present outbreak may have been a further example. Furthermore, adult liver flukes have been found in the common bile duct and removed during surgery for obstructive jaundice (O'Donnell, 1949; Murphy and Pascall, 1950; Ramage, 1951; Sagar, 1962; Munroe, 1965).

\section{The Outbreak}

All 44 patients admitted to having eaten wild watercress. from a bed, which was near infected cattle and sheep, during September and October 1968, some: two to three months before the onset of their symptome. The intermediate host, the snail Limnaea truncatula, was foind in the watercress bed concerned (Figs. 1 and 2). The degree of severe liver damage suffered by cattle is illustrated in a section of a calfs liver, which shows the gross macroscopic disorganization with thick cyst formation (Fig. : 3); in one cyst a fluke can be clearly seen. An adult form of the liver fluke is shown in Fig. 4.

The large number of cases discovered has given $\cdot$ us an opportunity to assess the difficulties in establishing an : exact diagnosis at the onset of the outbreak. Even when the possi-

- General Practitioner, Chepstow, Mon. bility of the correct diagnosis was considered, the typical diagnostic criteria were not always present in subsequently proved cases. Moreover, several completely asymptomatic cases were discovered solely by routine checking of possibly infected patients.

Symptomatology.-Manifestations of the illness were malaise, intermittent fever, night sweats, weight loss, and pain under the right costal margin. Urticaria with dermatographia was a distinctive feature in some of the cases. Coughing was an occasional symptom, and was sometimes severe and persistent though non-productive. Clinical jaundice was not generally noticed, and in several patients erroneous initial diagnoses were made early in the outbreak (see Table).

Investigations.-Laboratory investigations included full haematological examination; liver function and complement

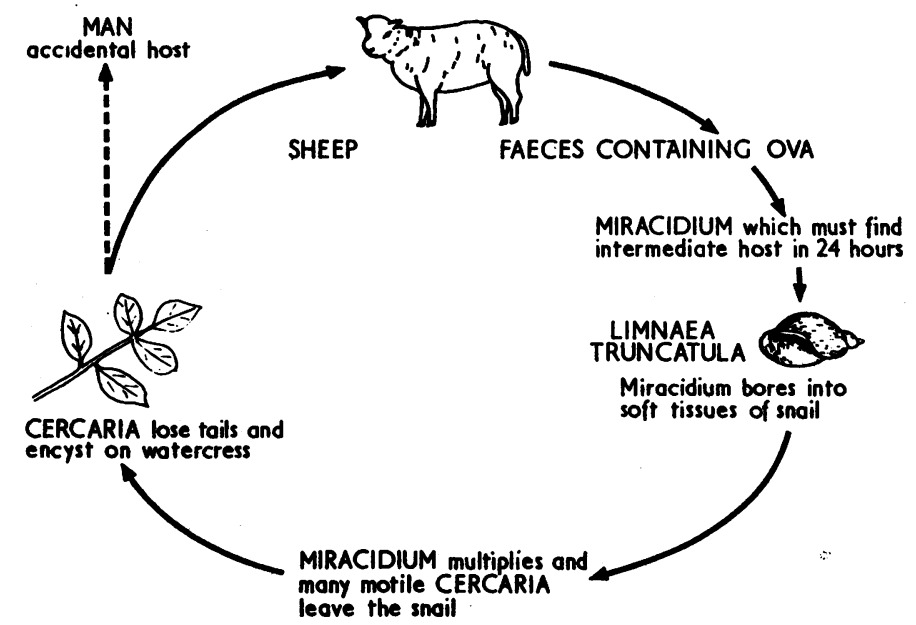

Fic. 1.-Life cycle of the liver fluke (Fasciola hepatica).

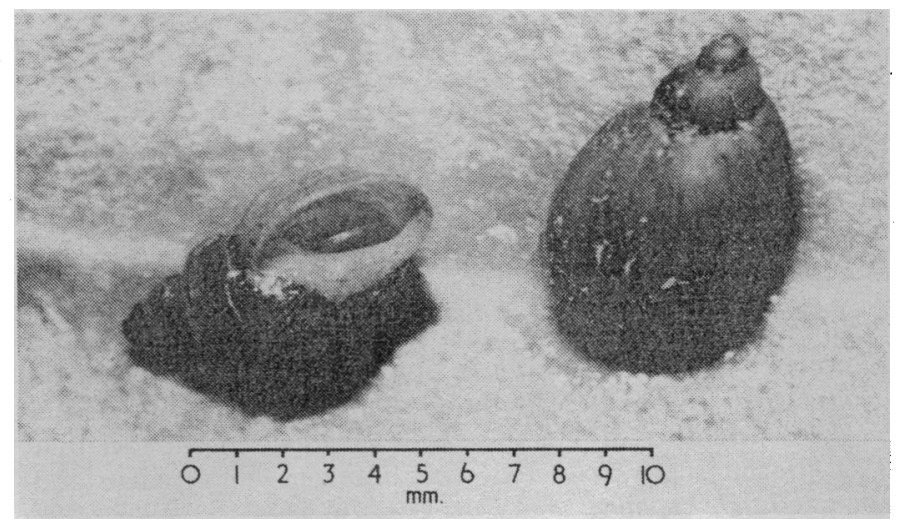

FIG. 2.-Intermediate host, the Limnaea truncatula. 